UDC: 633.34:581.1.1.035.2

DOI: $10.15587 / 2519-8025.2021 .229512$

\title{
EFFECTS OF E-GENES AND PHOTOPERIOD DURATION ON ASSIMILATION PROCESSES IN ISOGENIC LINES OF SOYBEAN
}

\author{
Yulia Yukhno, Vasyl Zhmurko
}

The aim of the research. To reveal the patterns of genetic control of assimilation processes in isogenic by E-genes lines of soybean conditions of different photoperiod duration.

Materials and methods. The plant material - 5 isolines of soybean (Glycine max (L.) Merr.) Cv. Clark: short-day (SD) lines (genotypes E1E2E3, E1e2e3) and neutral-day (ND) lines (genotypes elE2e3, ele2E3, ele2e3). From the third true leaf stage, one part of the plants was grown on a natural day (16 hours), and the other was exposed to a short day (9 hours). On the day of the start of the experiment, after 7 and 14 days, the dry weight of leaves and stems, the number and area of leaves were measured, based on which assimilation indices were calculated - RGR, NAR, LAR, SLA, LWR.

Results. During the studied ontogenetic period (two weeks) in all isolines, regardless of the genotype by E-genes and the duration of the photoperiod, the assimilation processes increased. The RGR and NAR under the short day decreased in the first week and then increased in the second week of the experiment. The degree of change in the indices varied depending on the isoline genotype by E-genes. The LAR and LWR were lower under the short day in SD lines. These indices were the same in the ND lines under short and long day. Under the short photoperiod the SLA in SD lines was higher, and in ND lines it was practically the same for both photoperiods.

Conclusions. The assimilation processes in the studied isogenic lines during the experience (two weeks) increase, but less intensively under short-day conditions. The studied lines, differed in the nature and intensity of assimilation processes, depending on the genotype by E-genes. Assimilation processes in the studied soybean lines are probably determined by the interaction of E-genes and the duration of the photoperiod, which is one of the important conditions for the adaptation of soybean to the environmental factors

Keywords: soybean (Glycine max (L.) Merr.), isogenic lines, E-genes, photoperiod, assimilation indices, growth, development

How to cite:

Yukhno, Y., Zhmurko, V. (2021). Effects of E-genes and photoperiod duration on assimilation processes in isogenic lines of soybean. ScienceRise: Biological Science, 1 (26), 32-39. doi: http://doi.org/10.15587/2519-8025.2021.229512

(C) The Author(s) 2021

This is an open access article under the Creative Commons CC BY license

\section{Introduction}

Cultivated soybean (Glycine $\max$ (L.) Merr.) is the most important food, industrial and fodder crop in the world. Its grain contains a complex of nutrients and biologically active substances, which determines such a variety of its use [1]. This crop is widely cultivated in Ukraine [2], but the highest yields of soybeans are obtained in the southern and southwestern regions of the country. This is due to the fact that cultivated soybeans are, by their biological nature, a thermophilic short-day plant $[1,3]$. For this reason, many of its highly productive varieties, when grown in regions with a photoperiod of more than 15-16 hours, has significantly slow down development. As a result, they form fruits and seeds late and, ultimately, ripen late or do not even reach full maturity, which significantly reduces the production efficiency of this valuable crop.

The basis of the production process of plants is their photosynthetic activity, which provides the basic physiological processes (growth, morphogenesis, formation of fruits and seeds) with plastic and energetic ma- terial [4]. The efficiency of this process is largely determined by the assimilation surface of the plant, which is formed during ontogenesis. Its formation depends on the interaction of the plant genotype and environmental factors. Among the environmental factors that determine the prevalence of plants in the growing zones, their adaptability, productivity and yield quality, the most important is the duration of the photoperiod $[5,6]$. This factor is most critical in relation to the growth, development and productivity of short-day plants, including cultivated soybeans.

To create new adaptive soybean varieties, it is very important to know about the patterns of assimilation processes, their possible genetic control under conditions of different photoperiod durations, since they ultimately determine the productivity of plants.

Previous studies with many soybean varieties have shown their diversity in response to the duration of the photoperiod [5]. Were identified varieties that practically did not change the rate of growth and development with a change in the duration of the photoperiod from 8 
to 16 hours and even up to round-the-clock lighting $[5,7]$. However, these experiments did not study the patterns of assimilation processes in soybeans. In addition, the use of soybean varieties makes it possible to state the presence of the effect of the genotype as a whole on the manifestation of the reaction to the duration of the photoperiod, but not of the specific genes that determine this reaction. In soybean, such genes ( $E$-series) have been identified and almost isogenic lines have been created, which differ in the state of the $E$ genes (dominant/recessive) with the same general genotype of the cultivar in the genophone of which they were created [8]. The allelic state of these genes determines the rate of development of soybeans under different photoperiodic conditions and determines its photoperiodic sensitivity [9]. The use of these lines as models makes it possible to reveal the possible effects of photoperiodic sensitivity genes on assimilation processes under conditions of different photoperiod duration.

\section{Literature review}

Plants respond to the duration of the photoperiod not only by changing the rate of development and the intensity of linear growth, but also by regulating the distribution of biomass between different organs, as well as by changing the structural and functional state of the assimilation apparatus $[10,11]$.

Soybeans by origin have a short-day photoperiodic reaction, however, varieties have been developed that have a neutral reaction to the duration of the photoperiod [12]. In the literature, there is a significant amount of data on the effect of the photoperiod on the duration of the growing season and the productivity of various soybean varieties. However, the overwhelming majority of the research has been aimed at studying the processes that occur during flowering [13] and are associated with the formation of the crop [14]. The main goal of these studies was to isolate genotypes with a weak response to the photoperiod in order to create varieties adaptive to this factor with high productivity of both seeds and vegetative mass. The growth parameters of various soybean varieties, based on assimilation indices, were also investigated during different phenophases [15]. However, the physiological aspects of the relationship between the duration of the vegetative phase, the process of distribution of biomass between different organs and the structural and functional state of the assimilation apparatus of soybeans with different duration of the photoperiod have not been sufficiently studied.

It has been shown that the adaptive plasticity of soybeans to different photoperiodic conditions is due to the allelic state of the $E$ genes in the genotype, which to varying degrees determine the photoperiodic reaction of soybeans [9]. The main phenotypic manifestations of the effects of these genes on the duration of the phases of soybean ontogenesis, mainly flowering, were revealed, as well as some effects of these genes on certain economically important traits under conditions of different photoperiod durations $[13,16]$. At the same time, the effects of $E$-genes on the assimilation parameters of soybean plants, which characterize the strategy of adaptation to different duration of the photoperiod, have not been studied.

\section{The aim and objectives of the study}

The aim of the study was to reveal the patterns of genetic control of assimilation processes in soybean lines isogenic for $E$ genes under conditions of different photoperiod duration.

Research objectives:

1. To establish the nature of changes in assimilation processes in the vegetative phase of ontogenesis of isolines under conditions of different photoperiods.

2. To reveal the influence of the duration of the photoperiod on the formation of assimilation processes (by assimilation indices).

3 . To establish the relationship between the genotype of soybean lines isogenic for genes $E$ with the course of assimilation processes under conditions of different duration of the photoperiod.

\section{Materials and methods}

The research material was the soybean lines (Glycine $\max (\mathrm{L}$.) Merr.) of the Clark variety, isogenic for the $E$ genes, kindly provided by the National Center for Plant Genetic Resources of Ukraine. These lines have a common genotype of the Clark cultivar, but differ in the allelic state of the E-genes: E1/e1, E2/e2, and E3/e3. These genes determine the photoperiodic sensitivity of the lines [17]. The experiment used short-day (SD) lines with genotypes E1E2E3, E1e2e3 and neutral-day lines (ND) with genotypes elE2E3, ele $2 e 3$. According to the results of our previous studies, under the influence of a short photoperiod, SD lines significantly shorten, and ND lines practically do not change the timing of the transition to flowering [18].

Plants were grown on the experimental site of the Department of Physiology and Biochemistry of Plants and Microorganisms of V.N. Karazin Kharkiv National University during the growing seasons of 2009-2012. Sowing was carried out manually in triplicate for each variant of the experiment at the optimal time for soybeans (third decade of April - first decade of May). The area of the accounting plot was $1 \mathrm{~m}^{2}$. At the stage of the third true leaf, some of the experimental plants were artificially darkened, reducing the length of the day to 9 hours (darkened from 18 to 9 hours with light-tight chambers). The second part of the plants was grown under natural long day conditions (about 16 hours at the latitude of Kharkov) during the entire experiment.

To study the assimilation process, we used assimilation indices, which reflect the effectiveness of the structural organization and functioning of the assimilation apparatus of plants, as well as the accumulation and distribution of organic matter between organs [19, 20]. By the nature of the change in these indices during the growing season or at its individual stages, one can judge, on the one hand, about the nature of the production process, and on the other, about the adaptability of plants to environmental factors.

To determine the assimilation indices on the day of the beginning of the reduction of the photoperiod, as well as after 7 and 14 days, the dry mass of aboveground plant organs, the number of leaves per plant, and leaf area were measured. The calculation of the leaf area was carried out by scanning it and processing the scanned copies using the "PhotoM 1.21" program. Based on these 
indicators, assimilation indices were calculated according to [21]:

- RGR (relative growth rate) - the relative growth rate is calculated by the formula: RGR (mg per day) = $=(\ln \mathrm{W} 2-\ln \mathrm{W} 1) /(\mathrm{t} 2-\mathrm{t} 1)$, where $\mathrm{W} 1$ and $\mathrm{W} 2$ are the dry weight of the plant at times $\mathrm{t} 1$ and $\mathrm{t} 2$.

- NAR (net assimilation rate) - the net assimilation rate is calculated by the formula: NAR $\left(\mathrm{g} / \mathrm{m}^{2}\right.$ per day $)=(1 / \mathrm{LA}) \times(\mathrm{dW} / \mathrm{dt})$, where LA is the leaf area $\left(\mathrm{m}^{2}\right)$, and $\mathrm{dW} / \mathrm{dt}$ is the change in dry weight of the plant $(\mathrm{g})$ per unit of time (day).

- LAR (leaf area ratio) - productivity of the leaf area is calculated by the formula: LAR $\left(\mathrm{m}^{2} / \mathrm{kg}\right)=$ $=(\mathrm{dLA} / \mathrm{dt}) /(\mathrm{dW} / \mathrm{dt})$, where $\mathrm{dLA} / \mathrm{dt}-$ change in leaf area (LA) by plant $\left(\mathrm{m}^{2}\right)$ for a certain period of time (day), and $\mathrm{dW} / \mathrm{dt}$ is the change in dry weight of the plant $(\mathrm{kg})$ for the same period of time (day).

- SLA (specific leaf area) - the specific leaf area is calculated as the ratio of the total area of all leaves $\left(\mathrm{m}^{2}\right)$ to the total dry mass of leaves from one plant $(\mathrm{kg})$.

- LWR (leaf weight ratio) - the mass fraction of leaves is calculated as the mass fraction of leaves from the total mass of the plant $(\mathrm{mg} / \mathrm{g})$.

Statistical data processing was performed by oneway analysis of variance using the Microsoft Office Excel 2003 program. The significance of the differences was assessed by the least significant difference $\left(\mathrm{LSD}_{0.05}\right)$. Since the patterns in the dynamics of the indicators of the studied processes in the years of research were similar, the figures show the average data (for 2010-2012) and their standard deviations.

\section{Research results}

An integral indicator of the response of plants to changing environmental conditions, including photoperiodic conditions, is the RGR index - relative growth rate. This indicator characterizes the relative rate of accumulation of organic matter per unit of time, and, in fact, is a criterion for the relative rate of increase in biomass [21].

The data of the RGR determination showed that the ontogenetic changes of this indicator did not depend on the length of the day and the genotype of the lines. Thus, for all lines, both at the 16-hour and at the 9-hour photoperiod, there was an increase in the relative growth rate by the end of the experiment. However, the level of this indicator differed in the investigated isolines and depended on the duration of the photoperiod (Fig. 1).

Thus, for the first week of the experiment under the conditions of a long day, the RGR was higher for all lines than on a short day. At the same time, the greatest decrease in RGR under the influence of a short day was observed in two SD lines E1E2E3 and E1e2e3 - 2.1 and 4.5 times, respectively $\left(\mathrm{LSD}_{0.05}=9.16 \mathrm{mg} /\right.$ day $)$. Only in ND line ele2E3 the RGR indices under different photoperiodic conditions practically did not differ $\left(\mathrm{LSD}_{0.05}=18.43 \mathrm{mg} /\right.$ day $)$ and were the highest among all isolines (Fig. 1).

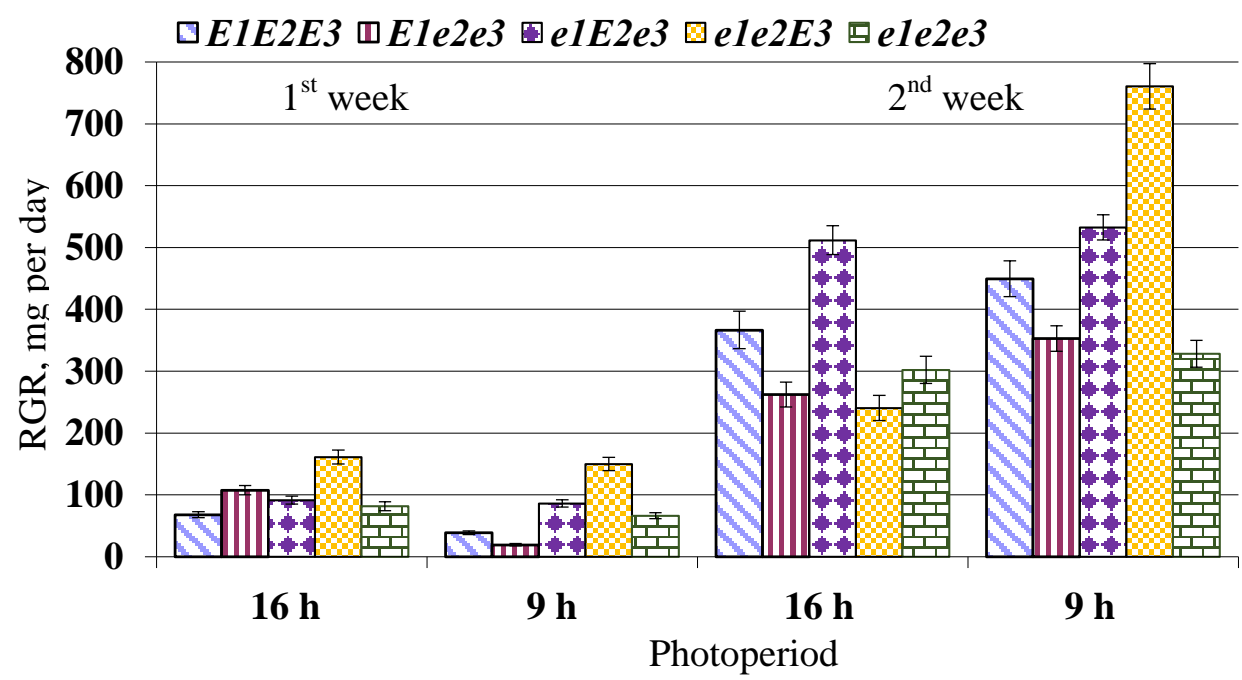

Fig. 1. Relative growth rate (RGR) of soybean lines isogenic for $E$-genes under conditions of different photoperiod duration

Over the next week of the experiment, in all lines, regardless of genotype and photoperiodic conditions, RGR significantly increased compared to its level in the first week of the experiment $\left(\mathrm{LSD}_{0.05}=67.94 \mathrm{mg} /\right.$ day $)$. However, a decrease in the photoperiod to 9 hours during this period led to a more significant increase in RGR, compared with an increase in this indices on a long day $\left(\mathrm{LSD}_{0.05}=50.34 \mathrm{mg} / \mathrm{day}\right)$, in lines with $E 1$ and/or $E 3$ in the genotype (Fig. 1). The largest difference in parameters was observed in ND line ele2E3, this difference was less in SD lines (E1E2E3 and E1e2e3). At the same time, two ND lines ele2e3 and especially elE2e3 were characterized by a high level of RGR both on long and short days equally $\left(\mathrm{LSD}_{0.05}=28.68 \mathrm{mg} /\right.$ day $)$. A high level of relative growth rate, according to some published data, can characterize a slowdown in the growth of the stem in length, compared with its growth in thickness [22]. This is consistent with our earlier results regarding the slowing down of linear growth in the studied soybean lines with a reduction in the photoperiod [18].

Differences in RGR levels can be explained by different ratios of the components of this indicator, namely, the assimilation component - NAR (net assimilation rate), and the morphological component - LAR (leaf area ratio) [20]. 
The value of net assimilation ratio (NAR) is an important element of the production process and characterizes the rate of accumulation of dry organic matter per unit of plant leaf surface per unit of time [23]. The results of NAR changes during the experiment are shown in Fig. 2, $a$.

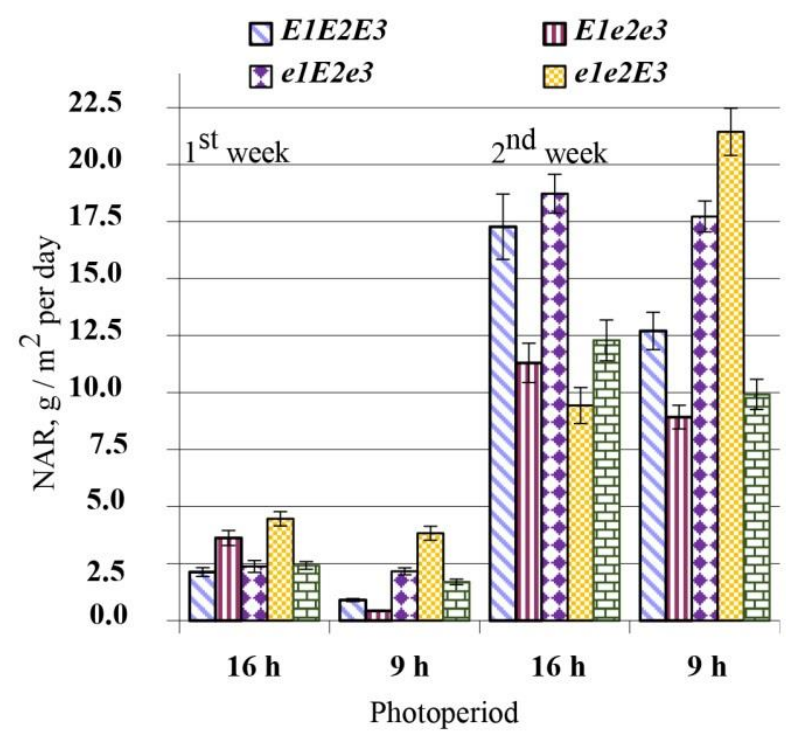

$a$

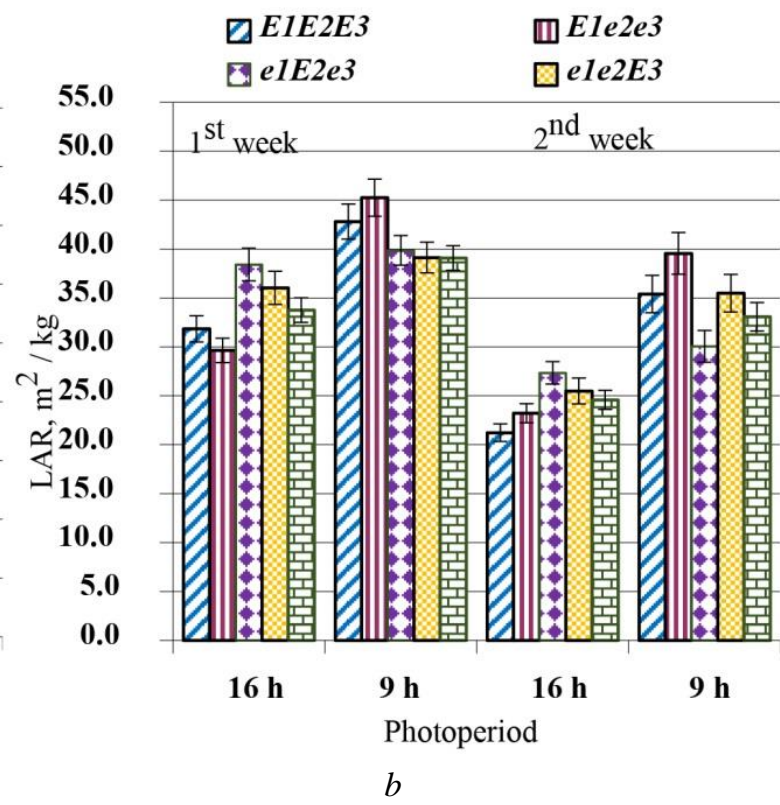

Fig. 2. Indicators of net assimilation rate (NAR) and productivity of leaf area (LAR) of soybean lines isogenic for $E$-genes under conditions of different photoperiod duration: $a-\mathrm{NAR} ; b-\mathrm{LAR}$

Based on our data, the level of the NAR index, which characterizes the physiological activity per unit of leaf area, depended on the duration of the photoperiod. In general, we can say that the trend of NAR variation during the experiment was the same as that of RGR, that is, during the first week of the experiment, regardless of photoperiodic conditions, this indicator increased for all isolines (Fig. 2,a).

However, it should be noted that the NAR index for the first week of the experiment was lower for all iso- lines on a short day (Fig. 2,a). The SD lines E1E2E3 and Ele $2 e 3$ had NAR on a short day the least of all, respectively 2.5 and 8.5 times less than on a long day $\left(\mathrm{LSD}_{0.05}=\right.$ $=0.68 \mathrm{~g} /\left(\mathrm{m}^{2} \times\right.$ day $\left.)\right)$. ND lines were characterized by a slight decrease in this indicator under the influence of a short photoperiod $\left(\mathrm{LSD}_{0.05}=0.93 \mathrm{~g} /\left(\mathrm{m}^{2} \times\right.\right.$ day $\left.)\right)$. For line elE2e3, no differences in NAR were observed on long and short days, which indicates the same rate of biomass accumulation in this isoline, regardless of the duration of the photoperiod (Fig. 2, $a$ ).

As shown above, in the second week of the experiment, all isolines showed an increase in NAR, regardless of photoperiodic conditions, but its degree was largely determined by the response of the genotype to photoperiodic conditions and the allelic state of the $E$-genes. Thus, in SD lines with the $E 1$ gene in the genotype (E1E2E3, E1e2e3), the rate of net assimilation was higher on a long day $\left(\mathrm{LSD}_{0.05}=0.82 \mathrm{~g} /\left(\mathrm{m}^{2} \times\right.\right.$ day $\left.)\right)$. In ND line ele $2 E 3$, on the contrary, NAR was higher under short day conditions, while short day had little effect on the NAR level of ND lines $e 1 E 2 e 3$ and $e 1 e 2 e 3\left(\mathrm{LSD}_{0.05}=0.7 \mathrm{~g} /\left(\mathrm{m}^{2} \times\right.\right.$ day $\left.)\right)$. At the same time, the $e 1 E 2 e 3$ line was characterized by the highest NAR values, and the ele2e3 line, on the contrary, has the lowest NAR among all the lines (Fig. 2, a).

The NAR index mainly characterizes the net increase in carbon assimilated during photosynthesis, and carbon losses (for respiration, excretion) per unit leaf area [19]. Therefore, high NAR values are determined by an increase in the rate of photosynthesis, which can occur due to the redistribution of assimilates in favor of the photosynthetic apparatus.

The LAR index level characterizes the productivity of the leaf apparatus, and, therefore, it can show its dependence on photosynthesis [23].

The obtained results showed that at the 16-hour photoperiod the LAR index for all lines for the first week of the experiment was lower than at the 9-hour photoperiod $\left(\mathrm{LSD}_{0.05}=1.65 \mathrm{~m}^{2} / \mathrm{kg}\right)$. This may indicate a more efficient work of the plant's photosynthetic apparatus under conditions of a long day (Fig. 2, b). Such differences in the LAR level were especially clearly observed in SD lines, in which this index on the long day was on average $11-14 \mathrm{~m}^{2} / \mathrm{kg}$ less than on the short one $\left(\operatorname{LSD}_{0.05}=\right.$ $=2.01 \mathrm{~m}^{2} / \mathrm{kg}$ ). This is due to the fact that the lower the LAR, the more organic matter is produced per unit of its leaf surface [19]. At the same time, ND lines, especially elE2e3, practically did not reduce the LAR level during the first week of the experiment with a reduction in the photoperiod to 9 hours $\left(\operatorname{LSD}_{0.05}=1.67 \mathrm{~m}^{2} / \mathrm{kg}\right)$. This can be explained by the fact that these lines probably use their photosynthetic resources with the same efficiency both on short and long days.

During the second week of the experiment, LAR decreases for all lines, regardless of photoperiodic conditions (Fig. 2, b). However, this decline was still more pronounced in the conditions of a long day. It should be noted that both for the first week of the experiment and for the second, the LAR index on the long day was higher for ND lines $\left(\mathrm{LSD}_{0.05}=1.3 \mathrm{~m}^{2} / \mathrm{kg}\right.$ ), and on the short day, on the contrary, was higher for SD lines $\left(\mathrm{LSD}_{0.05}=1.19 \mathrm{~m}^{2} / \mathrm{kg}\right)$. This difference in the dynamics of the LAR index in SD and ND soybean lines is due to the fact that they probably have different strategies in adapt- 
ing their photosynthetic apparatus to certain light conditions. This is determined by the fact that the productivity of the assimilation apparatus (LAR), in turn, is determined by two indicators: the specific leaf area (SLA) and the leaf weight ratio (LWR) [20].

The SLA index is the photosynthetic surface area that is formed per unit dry mass of plant leaves and demonstrates the efficiency with which the plant uses its photosynthetic resources [24].

According to our data for the first week of the experiment, the SLA index was higher under conditions of a short 9-hour photoperiod (Fig. 3, a), which confirms the literature data on an increase in SLA at low light intensity [11, 25-27]. However, this pattern was typical only for SD lines with genotypes E1E2E3 and E1e2e3 $\left(\mathrm{LSD}_{0.05}=3.27 \mathrm{~m}^{2} / \mathrm{kg}\right.$ ). All studied ND soybean lines had almost the same values of this indicator in the first week of the experiment, both on long and short days $\left(\operatorname{LSD}_{0.05}=3.45 \mathrm{~m}^{2} / \mathrm{kg}\right)$. This is most likely due to the fact that the formation of the assimilation apparatus of thees lines is largely determined by internal factors than by light conditions.

Further influence of both long and short photoperiods (the second week of the experiment) leads to a decrease in the SLA index for SD lines, but to a greater extent on a short day than on a long one $\left(\mathrm{LSD}_{0.05}=\right.$ $=1.67 \mathrm{~m}^{2} / \mathrm{kg}$ ). In ND lines, a slight decrease in SLA over this period of the experiment is observed only on the long day, and on the short day it remains at the level of the first week of the experiment $\left(\mathrm{LSD}_{0.05}=3.52 \mathrm{~m}^{2} / \mathrm{kg}\right.$ ).

Consequently, longer exposure to the 16-hour photoperiod (two weeks) resulted in a more significant decrease in SLA for all lines $\left(\mathrm{LSD}_{0.05}=1.35 \mathrm{~m}^{2} / \mathrm{kg}\right.$ ). This result is consistent with the conclusions of some authors $[11,25]$, which indicate that the availability of light is the main factor determining the level of the SLA index. However, as for the SD lines, their lack of light under the conditions of the 9-hour photoperiod was most likely compensated for by the high rate of photosynthesis.

The LWR indicates the fraction of total plant weight allocated to the leaves [24].

The results showed that for the first week of the experiment, the LWR index (Fig. 3, b) on a long day was higher in SD lines with genotypes E1E2E3 and E1e2e3 $\left(\mathrm{LSD}_{0.05}=35.28 \mathrm{mg} / \mathrm{g}\right)$ and almost the same in ND lines, compared to the level on the short day $\left(\mathrm{LSD}_{0.05}=\right.$ $=51.52 \mathrm{mg} / \mathrm{g}$ ).

The LWR index shows what part of the assimilates is spent on the creation of leaf biomass relative to the total plant biomass. Based on this, it can be assumed that, in the SD lines, with a reduction of the photoperiod in the first week, this proportion greatly decreases (almost 2 times) in comparison with the indicator on a long day. Accordingly, in ND lines, the proportion of assimilates spent on the creation of leaf biomass is approximately the same for both long and short photoperiods.
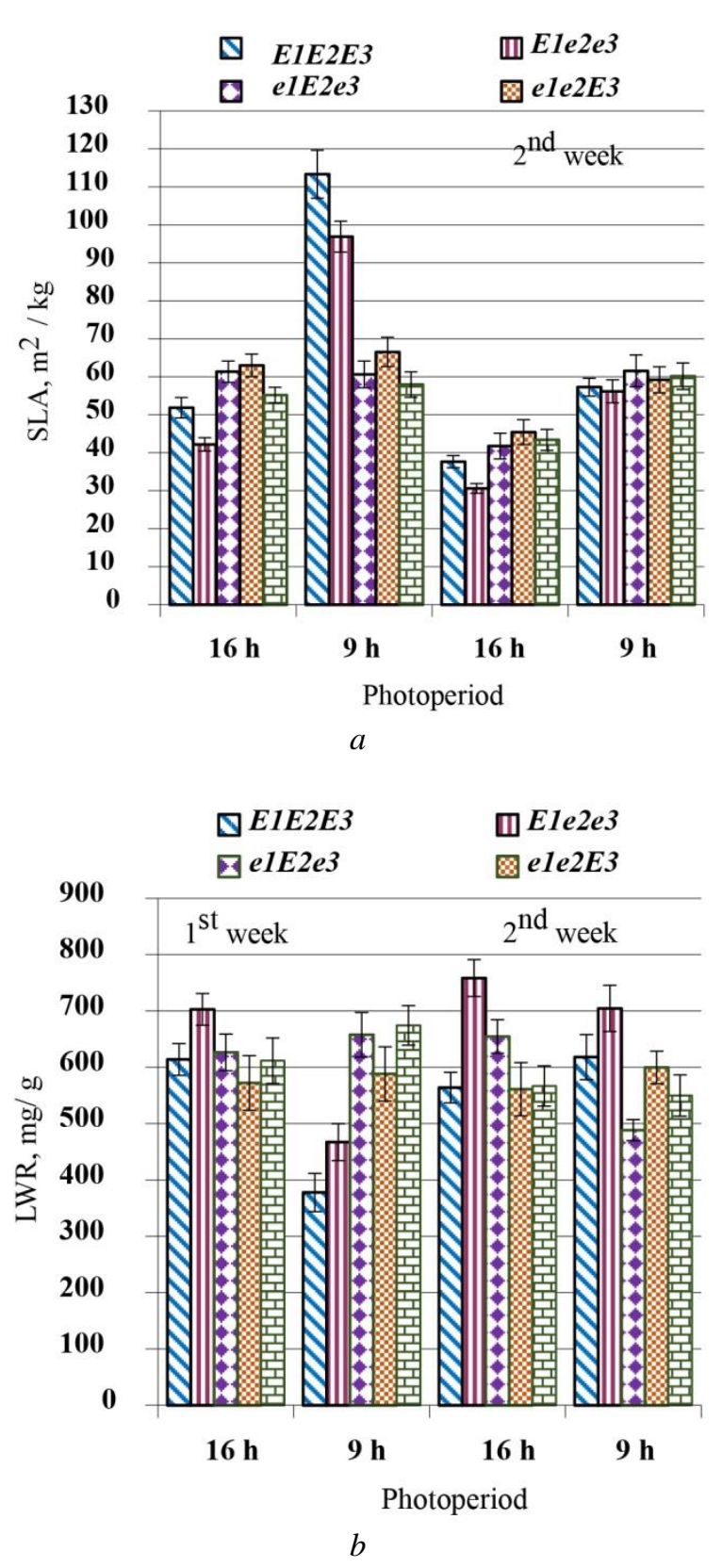

Fig. 3. Specific leaves area (SLA) and leaves weight ratio (LWR) of soybean lines isogenic for $E$-genes under conditions of different photoperiod duration:

$$
a-\mathrm{SLA} ; b-\mathrm{LWR}
$$

Over the next period of the experiment, the LWR changed significantly only under the influence of the short photoperiod to 9 hours (Fig. 3, b). Moreover, in SD lines, LWR increased (approximately 1.5-1.7 times) compared with the first week of the experiment $\left(\mathrm{LSD}_{0.05}=46.15 \mathrm{mg} / \mathrm{g}\right)$, while in ND lines, on the contrary, it decreased, but less significantly $\left(\mathrm{LSD}_{0.05}=37.67 \mathrm{mg} / \mathrm{g}\right)$. The effect of the 16-hour photoperiod practically did not lead to a change in LWR in all studied soybean lines during the second week of the experiment $\left(\mathrm{LSD}_{0.05}=53.60 \mathrm{mg} / \mathrm{g}\right)$.

As a result of such changes, the values of the LWR index in the studied lines under various photoperiodic condi- 
tions practically leveled off, with the exception of the ND line $e 1 E 2 e 3$, in which this indicator was lower on a short day than on a long day (Fig. 3, b). In addition, during the second week of the experiment, the SD lines on the short day had a higher LWR than the ND lines (LSD0.05=53.60 mg/g), especially in the Ele $2 e 3$ line (Fig. 3, b).

This character of changes in the SLA and LWR indices under contrasting photoperiodic conditions in soybean isolines is probably associated with the formation of a different strategy in their adaptation of the photosynthetic apparatus to certain light conditions. Moreover, this strategy is most likely determined by the photoperiodic reaction of the studied lines, which is controlled by the $E$ genes.

\section{Discussion}

The analysis of the obtained results showed that during the studied ontogenetic period (two weeks) in the lines, regardless of the genotype according to the allelic state of the $E$ genes and the duration of the photoperiod, the assimilation processes increased. This is probably due to an increase in the intensity of photosynthetic processes with the growth and development of plants. However, a reduction in the photoperiod had a modifying effect on assimilation processes. Thus, it was shown that the RGR index, which characterizes the relative rate of accumulation of organic matter per unit time, under the influence of a short photoperiod decreased in the lines in the first week of the experiment, and increased in the second week. The degree of change in this index was different depending on the genotype of the line by $E$ genes. A high level of the relative growth rate, according to some literature data, may characterize a slowdown in the growth of the stem in length, compared with its growth in thickness [22]. This is consistent with our earlier results regarding the slowing down of linear growth in the studied soybean lines with a reduction in the photoperiod [18]. Differences in the RGR indicators can be explained by the different ratio of the components of this indicator, namely the assimilation component, the net assimilation rate (NAR), and the morphological component, the productivity of the leaf area (LAR) [20].

Based on our data, the trend in NAR changes, which characterizes the physiological activity per unit leaf area, during the experiment was the same as the RGR. That is, during the experiment, the NAR index increased in all isolines, but the degree of increase was largely determined by the allelic state of the $E$-genes in the isoline genotype. Thus, in lines with El in the genotype (SD lines), NAR was higher on a long day than on a short one. And in lines with $e l$ in the genotype (ND line), this indicator was the same on long and short days. According to the literature, the NAR mainly characterizes the net result of carbon gain in the photosynthesis and carbon losses (for respiration, excretion) expressed per unit leaf area [19]. Therefore, high NAR values in lines can be associated with an increase in the rate of photosynthesis, which can occur due to the redistribution of assimilates in favor of the photosynthetic apparatus.

We have shown that under conditions of a long day, a more efficient work of the photosynthetic apparatus is observed in all lines. This is confirmed by lower LAR values under long day conditions, both in the first and second weeks of the experiment. According to our earlier data, this may be the result of a more intense increase in the number of leaves and their area in the studied lines on a long day than on a short one [18]. Many authors have shown that the change in the productivity of the area of the leaf apparatus is inversely related to the change in the light intensity [20,24]. Due to the fact that a reduction in the photoperiod leads to a decrease in the period of photosynthesis, less assimilates are formed. However, based on our data, this pattern was typical only for SD lines. In ND lines, a reduction in the photoperiod did not lead to an increase in LAR and, therefore, to a decrease in the intensity of organic matter formation per unit of leaf area.

The obtained results made it possible to assume that the studied soybean isolines, depending on their photoperiodic response, have a different strategy for the formation and functioning of the assimilation apparatus under conditions of a short (9 hours) photoperiod. Perhaps, in SD lines, this strategy manifests itself in the formation of a thinner leaf lamina, or a decrease in the mesophyll density, or both, which is reflected in an increase of the SLA index on a short day. This is most likely due to the fact that leaves form less biomass per unit area, which is reflected in a decrease of LWR under these photoperiodic conditions. In ND lines, the values of SLA and LWR indices on long and short days are approximately the same, which most likely indicates a rearrangement of the leaf mesostructure already in the first week of the experiment. According to the literature, such changes can lead to an increase in the number of mesophyll cells per unit leaf area in these lines and contribute to maintaining the rate of photosynthesis at approximately the same level as under conditions of a long day [23, 25].

The obtained results for the first time reveal some important aspects of the functioning of the assimilation apparatus under the genetic control of genes of soybean photoperiodic sensitivity under conditions of different duration of the photoperiod. They greatly expand the existing understanding of the assimilation processes in plants when environmental conditions change. Nevertheless, to deepen the understanding of the effect of different photoperiodic conditions on the assimilation processes of plants and, in particular, in soybeans, data on their effect on the formation of photosynthetic pigments, the formation of leaf mesostructure, and the intensity and productivity of photosynthesis are important.

Since assimilation processes largely reflect the course of the production process, the obtained results can be useful in substantiating methods for increasing the productivity of soybean plants, as well as in breeding when creating varieties of this crop with an increased level of adaptability to environmental factors.

Study limitations. The obtained results cannot fully characterize all the features of assimilation processes in soybean lines isogenic for $E$ genes under the influence of different duration of the photoperiod.

Prospects for further research. In the future, to expand the understanding of the patterns of assimilation processes in soybeans, it may make sense to study the content of photosynthetic pigments, the accumulation and distribution of carbohydrates in these isolines under contrasting photoperiodic conditions. 


\section{Conclusions}

1. Assimilation processes in the studied isogenic lines during the experiment (two weeks) increase, regardless of the photoperiodic conditions and the genotype of the lines by genes $E$. This is due to ontogenetic processes of formation of the assimilation surface.

2. A reduction in the duration of the photoperiod leads, as a rule, to a decrease in the assimilation indices, which is associated with a decrease in the duration of photosynthesis under these conditions.

3 . The studied lines, depending on the genotype for the $E$ genes, differed in the nature and intensity of assimilation processes. In lines with a short-day reaction (genotypes E1E2E3 and E1e2e3), changes in these processes are more pronounced than in neutral-day lines (genotypes elE2e3, ele2E3, ele2e3). The results ob- tained suggest that assimilation processes in the studied soybean lines are determined by the interaction of the genotype for $E$ genes and the duration of the photoperiod, which is one of the important external conditions for the adaptation of soybeans to environmental factors.

\section{Acknowledgment}

The work was carried out within the framework of the research theme "Study of molecular-genetic and physiological-biochemical mechanisms of vernalization and photoperiodic control of plant ontogenesis in vivo and in vitro", No. of state registration $0118 \mathrm{U} 002104$.

\section{Conflict of interests}

The authors declare that they have no conflicts of interest.

\section{References}

1. Vishnyakova, M. A., Seferova, I. V., Samsonova, M. G. (2017). Genetic sources required for soybean breeding in the context of new biotechnologies (review). Sel'skokhozyaistvennaya Biologiya, 52 (5), 905-916. doi: http://doi.org/10.15389/agrobiology.2017.5.905eng

2. World Agricultural Production (2020). United States Department of Agriculture. Circular Series. USDA, Foraing Agr. Servise. Available at: https://apps.fas.usda.gov/psdonline/circulars/production.pdf

3. Zhmurko, V. V., Avksentieva, O. O., Yukhno, Yu. Yu., Popova, Yu. V., Samoilov, A. M. Tymoshenko, V. F. et. al. (2017). Efekty heniv fotoperiodychnoi chutlyvosti i potreby v yarovyzatsii u roslyn pshenytsi miakoi ta soi kulturnoi. Fiziolohiia roslyn: dosiahnennia ta novi napriamy rozvytku. Kyiv: Lohos, 187-197.

4. Kyryzyi, D. A. (2004). Fotosyntez y rost rastenyi v aspekte donorno-aktseptornikh otnoshenyi. Kyiv: Lohos, 192. Kyiv, 43.

5. Zhmurko, V. V. (2009). Fizioloho-biokhimichni aspekty fotoperiodychnoho i yarovyzatsiinoho kontroliu rozvytku roslyn.

6. Andrés, F., Coupland, G. (2012). The genetic basis of flowering responses to seasonal cues. Nature Reviews Genetics, 13, 627-639. doi: http://doi.org/10.1038/nrg3291

7. Davydenko, O. H., Zhmurko V. V., Holoienko, D. V., Rozentsveih, V. E, Shablinska, O. V. (2004). Proiav fotoperiodychnoi reaktsii u rannostyhlykh sortiv soi. Selektsiia i nasinnytstvo, 88, 151-162.

8. Jiang, B., Nan, H., Gao, Y., Tang, L., Yue, Y., Lu, S. et. al. (2014). Allelic Combinations of Soybean Maturity Loci E1, E2, E3 and E4 Result in Diversity of Maturity and Adaptation to Different Latitudes. PLoS ONE, 9 (8), e106042. doi: http://doi.org/10.1371/journal.pone.0106042

9. Jung, C. H., Wong, C. E., Singh, M. B., Bhalla, P. L. (2012). Comparative genomic analysis of soybean flowering genes. PLoS One, 7 (6), e38250. Available at: doi: http://doi.org/10.1371/journal.pone.0038250

10. Meekins, J. F., McCarthy, B. C. (2000). Responses of the biennial forest herb Alliaria petiolata to variation in population density, nutrient addition and light availability. Journal of Ecology, 88, 447-463. doi: http://doi.org/10.1046/j.1365-2745.2000.00461.x

11. Dasti, A. A., Fatima, K., Malik, S. A. (2002). How photoperiod affects growth rate and biomass allocation pattern: a comparative study on three genotypes of Arabidopsis thaliana. Asian Journal of Plant Sciences, 1 (2), 176-179. doi: http://doi.org/10.3923/ajps.2002.176.179

12. Wang, Y., Wu, C-X., Zhang, X-M., Wang, Y-P., Han, T-F. (2008). Effects of Soybean Major Maturity Genes Under Different Photoperiods. Acta agronomica sinica, 34 (7), 1160-1168. doi: http://doi.org/10.3724/sp.j.1006.2008.01160

13. Han, T. F., Wang, J. L. (1995). Studies on the post-flowering photoperiodic responses in soybean. Acta Botanica Sinica, $37,863-869$.

14. Zhang, G., Du, W. (1999). The effects of daylength on the growth of soybean and the creation of wide-adaptation germplasm. Soybean Genetics Newsletter, 26. Available at: https://www.soybase.org/sgn/article.php?issue_id=2\&autoID=15

15. El-Darier, S., Hemada, M., Sadek, L. (2002). Dry Matter Distribution and Growth Analysis in Soybeans under Natural Agricultural Conditions. Pakistan Journal of Biological Sciences, 5 (5), 545-549. doi: http://doi.org/10.3923/pjbs.2002.545.549

16. Zhang, G. R. (1997). Photoperiod effects on growth and development periods and agronomic characteristics in soybean. Chinese Journal of Oil Crop Sciences, 19, 37-41.

17. Price, W. B. (2012). Understanding the Mechanisms of the Photoperiod Flowering Pathway in Soybean. University of Illinois at Urbana-Champaign, 94.

18. Yuhno, Yu. Yu., Zhmurko, V. V. (2010). The rates of development and the growth processes of soybean isogenic EElines under different day-length conditions. The Journal of V.N.Karazin Kharkiv National University. Series: biology, 905 (11), $217-223$.

19. Poorter, H. (2002). Plant growth and carbon economy. Encyclopedia of Life Sciences. doi: http://doi.org/10.1038/ npg.els.0003200

20. Sirtautas, R., Samuolienè, G., Brazaityte, A., Duchovskis, P. (2011). Temperature and photoperiod effects on photosynthetic indices of radish (Raphanus sativus L.). Zemdirbyste-Agric., 98, 57-62.

21. Hunt, R., Causton, D. R., Shipley, B. Askew, A. P. (2002). A modern tool for classical plant growth analysis. Annals of Botany, 90, 485-488. doi: http://doi.org/10.1093/aob/mcf214

22. Poorter, H., Anten, N. P. R., Marcelis, L. F. M. (2013). Physiological mechanisms in plant growth models: do we need a supra-cellular systems biology approach? Plant, Cell \& Environment, 36 (9), 1673-1690. doi: http://doi.org/10.1111/pce.12123

23. Koning, H., Lambers, H., Cambridge, M. L., Pons, T. L. (1989). Physiological and Morphological Differences Between Plants With High NAR or a High LAR as Related to Environmental Conditions. Causes and Consequences of Variation in Growth Rate and Productivity of Higher Plants. Academic Publishing, The Hague, 101-123. 
24. Poorter, H., van Rijn, C. P. E., Vanhala, T. K., Verhoeven, K. J. F., de Jong, Y. E. M., Stam, P., Lambers, H. (2004). A genetic analysis of relative growth rate and underlying components in Hordeum spontaneum. Oecologia, 142 (3), 360-377. doi: http://doi.org/10.1007/s00442-004-1705-1

25. Anten, N. P. R., Hirose, T. (1999). Inter-specific differences in above ground growth patterns results in spatial and temporal partitioning of light among species in tall-grass meadow. Journal of Ecology, 87 (4), 583-597. doi: http://doi.org/10.1046/j.13652745.1999.00365.x

26. Caliskan, O., Odabas, M. S., Cİrak, C., Radušienė, J., Odabas, F. (2010). The quantitative effect of temperature and light intensity at growth in Origanum onites L. Journal of Medicinal Plants Research, 4 (7), 551-558.

27. Bunce, J. A., Heichel, G. H. (1986). Measurements and modeling of photosynthesis in field crops. Critical Reviews in Plant Sciences, 4 (1), 47-77. doi: http://doi.org/10.1080/07352688609382218

Received date 05.01.2021

Accepted date 11.02.2021

Published date 31.03.2021

Yulia Yukhno, Senior Lecturer, Department of Physiology and Biochemistry of Plants and Microorganisms, V. N. Karazin Kharkiv National University, Svobody sq., 4, Kharkiv, Ukraine, 61022

E-mail: yu.yu.yukhno@karazin.ua

Vasyl Zhmurko, Doctor of Biological Sciences, Professor, Department of Physiology and Biochemistry of Plants and Microorganisms, V. N. Karazin Kharkiv National University, Svobody sq., 4, Kharkiv, Ukraine, 61022

E-mail: zhmurko@karazin.ua 